\title{
Women with Severe Anemia in Labor: Fetomaternal Outcomes
}

\author{
Priyanka Bansal $^{1}$, Anand Singhal ${ }^{2}$ \\ ${ }^{1}$ Senior Resident, Obstetrics and Gynaecology, Kalpana Chawla Government Medical College Karnal, Haryana \\ ${ }^{2}$ Senior Consultant, General Medicine, Kaushal Hospital, Mohali, Chandigarh \\ Corresponding Author: Priyanka Bansal
}

DOI: https://doi.org/10.52403/ijhsr.20220101

\begin{abstract}
Background: Anaemia in pregnancy is the leading medical disorder in developing countries like India. Women with severe anemia in labor is a challenging situation for the obstetrician with increased maternal and perinatal morbidity and mortality. It has multifactorial etiology, Main cause of anemia in obstetrics is iron deficiency. There are specific risks for the mother like preterm labour pain, IUGR baby, preeclampsia, antepartum haemorrhage, sepsis etc and the fetus such as prematurity, low birth weight, birth asphyxia etc.

Aim and Objectives: To determine the socio-demographic variables and also the maternal and perinatal outcomes of pregnant women admitted to labour room with severe anemia ( $\mathrm{Hb}<7 \mathrm{gm} \%$ ) late in pregnancy.

Results: It was seen that out of 50 severely anemic women, 82\% had Hb between 4-7 gm\% and 18\% had $\mathrm{Hb}<4 \mathrm{gm} \%$. Severe anemia is seen in $82 \%$ unbooked patients and only in $18 \%$ booked patients. There was increased incidence of preterm delivery, $\mathrm{PPH}$, preeclampsia, eclampsia, mortality in anemic group as compared to non anemic group. Among the adverse fetal outcomes, there was increased incidence of intrauterine deaths, intrauterine growth restriction, NICU admission, low birth weight among the anemic group as compared to non anemic group.

Conclusions: Severely anemic women reporting in labor had significantly high maternal and perinatal morbidity and mortality. Even a minor blood loss is much devastating for such patients. Extrapolating our observations, it can be said that a close vigilance, anticipation of complications and appropriate care and interventions during labor and puerperium will help in improving outcomes in these severely anemic women. Awareness and education on early antenatal bookings, regular iron intake and continuous antenatal care should be the goal in tackling anemia in pregnancy.
\end{abstract}

Keywords: Anaemia, Iron deficiency, Intrauterine growth retardation, prematurity, maternal outcome, neonatal outcome

\section{INTRODUCTION}

Anemia in pregnancy is a major public health problem throughout the world, particularly developing country like India. ${ }^{1}$ The prevalence of anemia during pregnancy is $18 \%$ in developed countries as against $56 \%$ in developing nations. ${ }^{2}$ The prevalence of anemia during pregnancy in India is $87 \%$ which is quite high. ${ }^{3}$ Severely anemic women in labor is a challenging situation for the obstetrician with increased perinatal and maternal morbidity and mortality.

World health organization defines anaemia as haemoglobin less than $11 \mathrm{gm} / \mathrm{dl}$ in first and third trimester and less than 10.5 gm/dl in second trimester. ${ }^{4}$

Anaemia is further classified into mild, moderate and severe by ICMR depending upon the levels of hemoglobin.

1> Mild: Hb 10-10.9gm/dl

2> Moderate : Hb 7-10 gm/dl 
3> Severe: $\mathrm{Hb}$ 4-7 gm/dl

4> Very severe: less than $4 \mathrm{gm} / \mathrm{dl}$

Severe anemia in women who are already in labor is a critical situation for the obstetrician with the risk of adverse fetomaternal outcomes. It is responsible for $20-40 \%$ of direct and indirect maternal deaths because of increased susceptibility to cardiac failure, sepsis and association with preeclampsia, antepartum haemorrhage, postpartum haemorrhage and thromboembolism. ${ }^{5,6}$

Risk of preterm delivery, low birth weight, prematurity, intrauterine growth retardation, intrauterine death and birth asphyxia is increased causing increased perinatal morbidity and mortality. . $^{5}$

Anemia has multifactorial etiology. ${ }^{8}$

Nutritional anemia is more common i.e. inhibitors of iron absorption, dietary deficiency of iron, folic acid and vitamin B12. During pregnancy, fetal and placental growth and larger amount of circulatory blood leads to the increased demand for nutrients, especially iron and folic acid. Other factors are pregnancy iron deficiency, teenage pregnancy, lack of appropriate spacing between pregnancies, parasitic infestation (e.g. malaria, hookworm infestation), poor environmental and personal hygiene. ${ }^{9}$

Most of the women are uneducated or not well educated, have low socioeconomic status and are unbooked, prevention has little role when these severely anemic women are seen during labor. Anemic women present at the time of labour is a difficult task for the treating obstetrician because even a little blood loss at the time of delivery might prove life threatening. Moreover, if it has been diagnosed early in pregnancy corrective measures can be taken.

Aim and objective: To evaluate maternal and fetal outcomes in pregnant women in severe anemia and pregnant women without anemia reporting in labor.

\section{MATERIAL AND METHODS}

This is retrospective study conducted for six months from June 2021 to November 2021 in the Department of Obstetrics and Gynaecology at tertiary care hospital. Data was collected from medical records. One hundred women were studied, 50 women in each group. Group A (Study group): women with hemoglobin < 7gm/dl and Group B (Control group): women with hemoglobin $\geq$ $11 \mathrm{gm} / \mathrm{dl}$ ) fulfilling inclusion and exclusion criteria.

\section{Inclusion criteria:}

1. Pregnant women with $\mathrm{Hb}<7 \mathrm{gm} / \mathrm{dl}$ in labor (Group A/ Study group).

2. Pregnant women with $\mathrm{Hb} \geq 11 \mathrm{gm} / \mathrm{dl}$ in labor (Group B/ Control group).

\section{Exclusion criteria:}

1. Pregnant women with hemoglobin between 7- $10.9 \mathrm{gm} / \mathrm{dl}$.

2. Women with severe anemia at term or at the time of delivery due to acute bleeding (Antepartum haemorrhage).

3. History of hemoglobinopathy.

4. Multiple pregnancy.

5. Pregnant women with pre-existing medical co-morbidities like hypertension, diabetes, cardiac disease.

Medical records of patients fulfilling the inclusion were studied for maternal age, parity, booking status, gestational age, preeclampsia, low birth weight, NICU admission, fetal demise, postpartum hemorrhage, maternal intensive care, maternal mortality.

\section{RESULT}

There was total 80 patients with severe anemia in labor who met the inclusion criteria, out of which 50 were taken as study group (Group A). Out of these 50 patients, 41 (82\%) patients had $\mathrm{Hb}$ between 4-7 gm\%, 9 (18\%) patients had $\mathrm{Hb}$ $<4$ gm\%. 50 random patients in labor with $\mathrm{Hb} \geq 11 \mathrm{gm} \%$ fulfilling inclusion criteria were taken as control group (Group B). 
Table 1. Patients' characteristics

\begin{tabular}{|c|c|c|}
\hline Criteria & Group A & Group B \\
\hline \multicolumn{3}{|l|}{$\mathrm{Hb}(\mathrm{gm} \%)$} \\
\hline$\geq 11$ & $0(0 \%)$ & $50(100 \%)$ \\
\hline $7-11$ & $0(0 \%)$ & $0(0 \%)$ \\
\hline $4-7$ & $41(82 \%)$ & $0(0 \%)$ \\
\hline$<4$ & $09(18 \%)$ & $0(0 \%)$ \\
\hline \multicolumn{3}{|l|}{ Age group (years) } \\
\hline$<25$ & $24(48 \%)$ & $22(44 \%)$ \\
\hline $25-29$ & $18(36 \%)$ & $20(40 \%)$ \\
\hline$\geq 30$ & $9(18 \%)$ & $8(16 \%)$ \\
\hline \multicolumn{3}{|l|}{ Booking status } \\
\hline Booked & $9(18 \%)$ & $43(86 \%)$ \\
\hline Unbooked & $41(82 \%)$ & $7(14 \%)$ \\
\hline \multicolumn{3}{|c|}{ Gestational status (Weeks) } \\
\hline $37-42$ & $32(64 \%)$ & $47(94 \%)$ \\
\hline $34-37$ & $14(28 \%)$ & $2(4 \%)$ \\
\hline$\leq 34$ & $4(8 \%)$ & $1(2 \%)$ \\
\hline \multicolumn{3}{|l|}{ Gravida } \\
\hline Primigravida & $16(32 \%)$ & $28(56 \%)$ \\
\hline Multigravida & $34(68 \%)$ & $22(44 \%)$ \\
\hline \multicolumn{3}{|l|}{ Socioeconomic status } \\
\hline Lower & $38(76 \%)$ & $1(2 \%)$ \\
\hline Middle & $12(24 \%)$ & $41(82 \%)$ \\
\hline Upper & $0(0 \%)$ & $8(16 \%)$ \\
\hline \multicolumn{3}{|l|}{ Education } \\
\hline Illiterate & $28(56 \%)$ & $1(2 \%)$ \\
\hline Primary school & $18(36 \%)$ & $9(18 \%)$ \\
\hline Secondary school & $3(6 \%)$ & $35(70 \%)$ \\
\hline Pg/ Graduate & $1(2 \%)$ & $5(10 \%)$ \\
\hline
\end{tabular}

In table 1 , out of 50 patients in group A, $82 \%$ patients had $\mathrm{Hb}$ between $4-7 \mathrm{gm} \%$ and $18 \%$ had $\mathrm{Hb}<4 \mathrm{gm} \%$. In group $\mathrm{B}$, all patients had $\mathrm{Hb} \geq 11 \mathrm{gm} \%$. In group $\mathrm{A}, 56 \%$ women were illiterate as compared to $2 \%$ illiteracy rate in group B. Maximum women in group $\mathrm{A}$ belonged to low socioeconomic status (76\%) as compared to group B, in which maximum women (82\%) belonged to middle class. In group A, 68\% women are multigravida and $32 \%$ women were primigravida while in group B, $44 \%$ women were multigravida and $56 \%$ were primigravida.

Table 2. Obstetric outcomes

\begin{tabular}{|l|c|c|}
\hline Mode of delivery & Group A & Group B \\
\hline Vaginal & $40(80 \%)$ & $43(86 \%)$ \\
\hline Instrumental delivery & $2(4 \%)$ & $1(2 \%)$ \\
\hline LSCS & $8(16 \%)$ & $6(12 \%)$ \\
\hline
\end{tabular}

In group A, 16\%women underwent Lscs, $80 \%$ delivered vaginally, 4\% had instrumental delivery. In group B, 12\% women underwent Lscs, 86\% delivered vaginally and $1 \%$ had instrumental delivery. There is no significant difference in mode of delivery in anemic and non anemic women.

Table 3. Maternal complications

\begin{tabular}{|l|c|c|}
\hline \multicolumn{1}{|c|}{ Complications } & Group A & Group B \\
\hline Preterm labor & $23(46 \%)$ & $3(6 \%)$ \\
\hline Preeclampsia- Eclampsia & $12(24 \%)$ & $2(4 \%)$ \\
\hline IUGR & $9(18 \%)$ & $2(4 \%)$ \\
\hline Intrauterine fetal death & $2(4 \%)$ & $0(0 \%)$ \\
\hline Postpartum Hemorrhage & $5(10 \%)$ & $1(2 \%)$ \\
\hline ICU admission & $5(10 \%)$ & $0(0 \%)$ \\
\hline Cardiac failure & $2(4 \%)$ & $0(0 \%)$ \\
\hline Postoperative fever and infection & $6(12 \%)$ & $1(2 \%)$ \\
\hline Maternal mortality & $1(2 \%)$ & $0(0 \%)$ \\
\hline
\end{tabular}

Table 3 depicts that all maternal complications were higher in group A. Preterm labor (46\%) was the most common complication followed by preeclampsia (24\%) and IUGR (18\%).

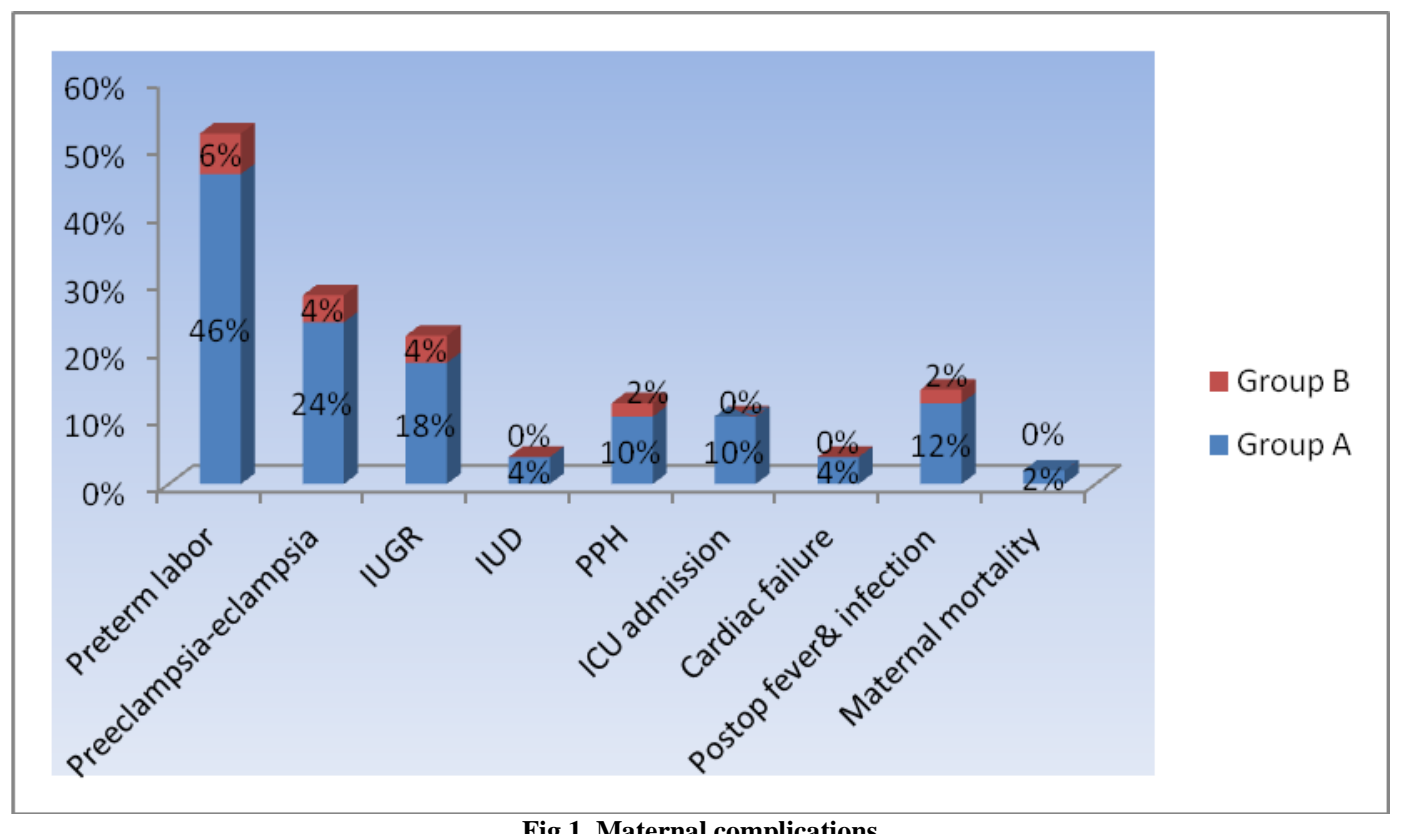

Fig 1. Maternal complications 
Table 4. Neonatal complications

\begin{tabular}{|c|c|r|}
\hline Complications & Group A & Group B \\
\hline Prematurity & $23(46 \%)$ & $3(6 \%)$ \\
\hline NICU admission & $13(26 \%)$ & $2(4 \%)$ \\
\hline Perinatal death & $2(4 \%)$ & $0(0 \%)$ \\
\hline Birth asphyxia & $5(10 \%)$ & $3(6 \%)$ \\
\hline Low birth weight & $14(28 \%)$ & $4(8 \%)$ \\
\hline
\end{tabular}

All neonatal complications, like prematurity, NICU admission, perinatal death, low birth weight etc were higher in babies who belonged to group A women as compared to babies who belonged to group B women (Table4).

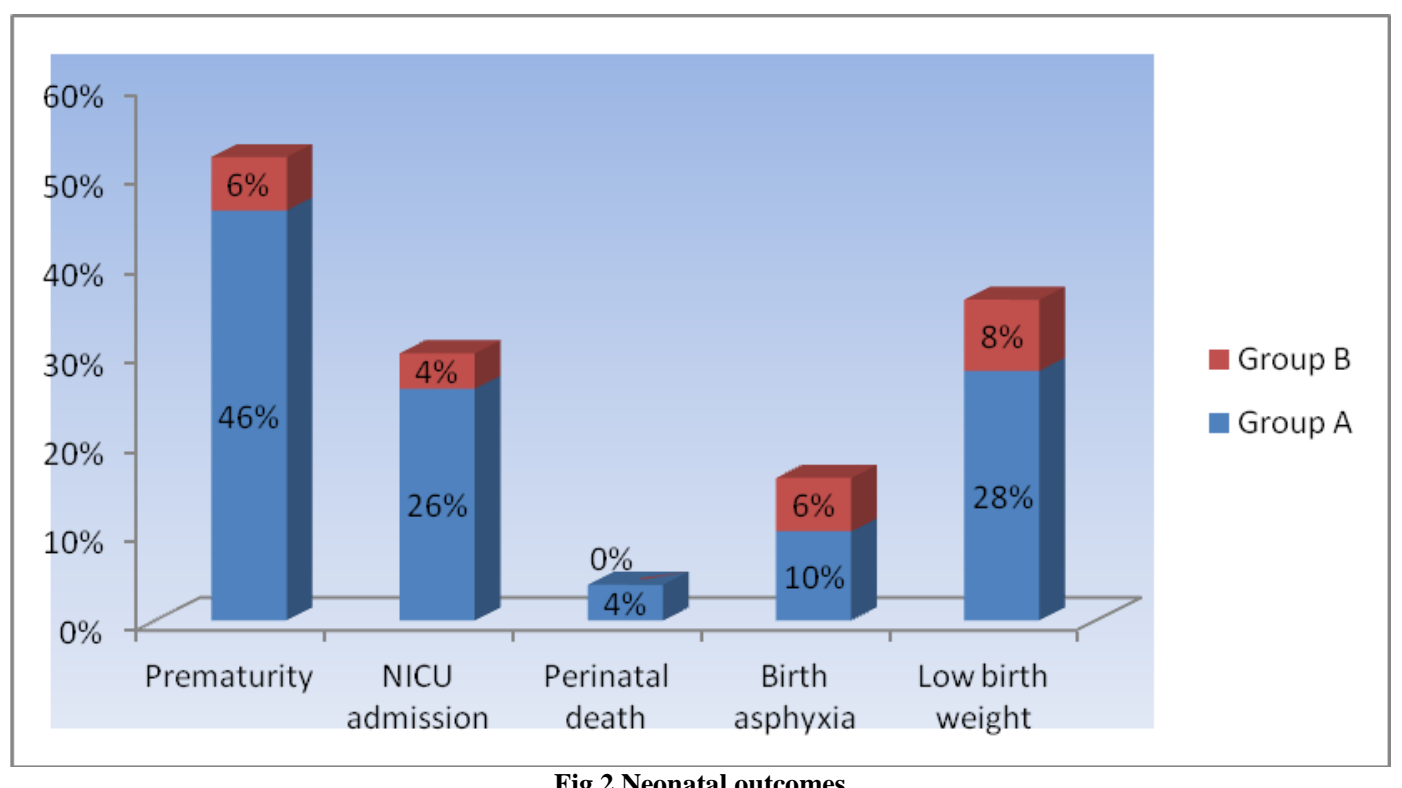

\section{DISCUSSION}

Anemia in pregnancy is the major health issue in rural part of India due to various reasons like poverty, illiteracy, lack of awareness about the need for antenatal care and presence of superadded infections. Anemia in pregnancy is the risk factor for preterm labour, intrauterine growth restriction, cardiac failure, puerperal sepsis, sub-involution and failure of lactation. ${ }^{10}$ Severe anemia in pregnancy has a significant impact on maternal and perinatal outcomes. Severity of anemia is an independent risk factor for preeclampsia, low birth weight. ${ }^{11}$

While studying the age pattern of pregnant women it was observed that the majority of women in both the groups belonged to 20-25 years age group which is common reproductive age group. 48\% patients in group $\mathrm{A}$ and $44 \%$ patients in group B belonged to age group 20-25 years of age group. So in present study, age was not a risk factor for anemia. Owais MA et $\mathrm{al}^{12}$ had similarly concluded in the study that age was no longer associated with increased risk of anemia when adjusted with gravidity.

The prevalence of severe anaemia was higher in unbooked patients which is similar to studies conducted by Singh $\mathrm{S}$ et $\mathrm{al}^{13}$ and Batar et $\mathrm{al}^{14}$. The booked patients benefit from focused antenatal care objectives, which reduce maternal and fetal morbidity and mortality, and have obvious benefits in terms of risk assessment, active management, correction of modifiable conditions, and enhance psychological support. $18 \%$ booked patients had severe anemia which could be due to noncompliance with iron therapy and lack of frequent haemoglobin estimation.

In severely anemic group, proportion of multigravida was more i.e. $68 \%$ as compared to primigravida which was $32 \%$. This was because with increasing number of pregnancies, iron stores get depleted. Many of them never have regained a good blood picture, and anemia persists, and worsens with subsequent pregnancies. This was consistent with the study of Viengsakhone L 
et $\mathrm{al}^{15}$, which showed that parity is a significant risk factor.

In our study, all maternal and neonatal complications were higher in women with severe anemia compared to non anemic women which is comparable to studies conducted by other authors.

In this study, $46 \%$ of women in group A had preterm delivery which is comparable to study conducted by Singhal et $\mathrm{al}^{16}$ and Devi NB et $\mathrm{al}^{17}$, who also observed that $32 \%$ and $44.7 \%$ women had preterm delivery respectively. Low haemoglobin levels may cause a state of low-grade chronic hypoxia which induces maternal and fetal stress. An activated immune system in the presence of infections and inflammation and corticotrophin releasing hormone or cortisol that are released following stress response can activate the maternal or fetal hypothalamicpituitary-adrenal axis. Iron deficiency may also increases oxidative stress resulting in damage to erythrocytes and the fetoplacental unit. This in turn can initiate labor and eventually result in preterm parturition.

PPH was significantly more common in severely anaemic patients (10\% in group A versus $2 \%$ in group B). Severe anaemia may impair the myometrial contractility resulting from impaired transport of oxygen to uterus causing tissue enzymes and cellular dysfunction, leading to increased risk of atonic PPH. This result is comparable with study conducted by Riffat Jaleel et $\mathrm{al}^{18}$ who also observed PPH in $9.8 \%$ anemic women. Devi NB et $\mathrm{al}^{17}$ observed $\mathrm{PPH}$ in $6.8 \%$ severely anemic women.

In our study, incidence of hypertensive disease of pregnancy was significantly higher in group A (24\%) as compared to group B (4\%). Batar et $\mathrm{al}^{14}$ and Devi NB et $\mathrm{al}^{17}$ also reported preeclampsia in $20 \%$ and $25.3 \%$ severely anemic women respectively. The susceptibility of women with severe anaemia to preeclampsia could be explained by a deficiency of micronutrients and antioxidants. Reduction in serum levels of calcium, magnesium and zinc during pregnancy might be possible cause for the development of preeclampsia.

Besides preeclampsia, the effect of maternal anemia on intrauterine growth is attributed to chronic deprivation of oxygen to the developing fetus. If severe maternal anemia present from early gestation, may be associated with reduced placental weight and surface area of peripheral villi which is determinant of nutrient transport from the mother to the fetus. IUGR was seen in $10 \%$ cases in our study which was comparable to study conducted by Devi $\mathrm{NB}$ et $\mathrm{al}^{17}$ and Singhal et $\mathrm{al}^{16}$ who depicted that $12.8 \%$ and $6.6 \%$ severely anemic women had IUGR babies respectively. The results of present study correlate well with Devi NB et $\mathrm{al}^{17}$ and Singhal et $\mathrm{al}^{16}$ study.

To conclude, in the present study severe anemia was more prevalent in unbooked, multiparous, low socioeconomic status pregnant females. Prematurity followed by preeclampsia and IUGR were major maternal complications. All neonatal complications like prematurity, low birth weight, birth asphyxia, NICU admission etc were higher in babies belong to anemic women compared to non anemic women.

\section{CONCLUSION}

Severely anemic women reporting in labor had significantly high maternal and perinatal morbidity and mortality. Even a minor blood loss is devastating for such patients. Extrapolating our observations, it can be said that a close vigilance, anticipation of complications and appropriate care and interventions during labor and puerperium will help in improving outcomes in these severely anemic women. Awareness and education on early antenatal bookings, regular iron intake and continuous antenatal care be the goal in tackling anemia in pregnancy.

Acknowledgement: None

Conflict of Interest: None

Source of Funding: None 


\section{Ethical Approval: Approved}

\section{REFERENCES}

1. McLean E, Cogswell M, Egli I, Wojdyla D, de Benoist $\mathrm{B}$. Worldwide prevalence of anaemia, WHO Vitamin and mineral Nutrition Information System, 1993-2005. Public Health Nutr. 2009;12:444-54.

2. Kalaivani K. Prevalence and consequences of anaemia in pregnancy. Indian J Med Res. 2009;130:627-33.

3. Mangla M, Singla D. Prevalence of anaemia among pregnant women in rural India: a longitudinal observational study. Int $\mathrm{J}$ Reprod Contracept Obstet Gynecol. 2016;5:3500-5.

4. WHO (2001) Iron deficiency anemia: assessment, prevention and control. WHO/NHD/0.13, Geneva. World Health Organisation, Switzerland.

5. Suryanarayana R, Chandrappa M, Santhuram AN, Prathima S, Sheela SR. Prospective study on prevalence of anemia of pregnant women and its outcome: A community based study. J of Family Med Prim care. 2017; 6(4): 739-743.

6. Maka SS, Tondare SB, Tondare MB. Study of impactof anemia on pregnancy. Int.J Reprod Contracept Obstet Gynecol. 2017; 6(11): 4847-4850.

7. Sangeetha VB, Pushpalatha.S. Severe Maternal Anemia and Neonatal outcome Sch J App Med Sci 2014; 2 (1c): 303-309.

8. VanderJagt DJ, Brock HS, Melah GS, ElNafaty AU, Crossey MJ, Glew RH. Nutritional factors associated with anaemia in pregnant women in northern Nigeria. J Health Popul Nutr. 2007 Mar;25:75-8.

9. Mallika S, Valrmathi. Prevalence of anemia in pregnancy: A retrospective study at tertiary care hospital in Sivangangai, Tamilnadu, India. Int J Sci Res 2018;7:426.
10. Sabina S, Iftequar S, Zaheer Z, Khan M, Khan S. An overview of anemia in pregnancy. JIPBS. 2015;2:144-51.

11. Karaoglu L, Pehlivan E, Egri M, Deprem C, Gunes G, Genc MF et al. The prevalence of nutritional anemia in pregnancy in an east Anatolian province, Turkey. BMC Public Health. 2010;10:329.

12. Owais MA, Kalsoom U. Effect of maternal anameiaon birth weight. J Ayub Med Coll Abbottabad.2011;23.

13. Singh S, Kaur K. Maternal outcome in cases of severe anaemia in labour. Int J Reprod Contracept Obstet Gynecol. 2018; 7: 12011204.

14. Batar A, Salvi A, Saini L, Agarwal S, Rajoria L and Mital P. Maternal and Perinatal Outcome of Pregnancy with Severe Anaemia. International Journal of Biomedical and Advance Research 2015; 6: 611-616.

15. Viengsakhone L, Yoshida Y, Harun-OrRashid M,Sakamoto J. Factors affecting low birth weight at four central hospitals in vientiane, Lao PDR.Nagoya. J Med Sci. 2010;72:51-8.

16. Singhal SR N, S.Mandira. Sangwank. Sharma D. Maternal and Perinatal outcome in severe Anaemia. Indian Practitioner, 2007;.No.60:691-4.

17. Devi NB, Varalaxmi B, Jyothirmayi T, Lahari N. Maternal outcome in pregnancy with severe anaemia: Prospective study in a tertiary care hospital in Andhra Pradesh. IOSR-JDMS. 2015;14:6-10.

18. Jaleel RI, Khan A. Severe anemia and adverse pregnancy outcome J Surg Pak. 2008;13:147-50.

How to cite this article: Bansal P, Singhal A. Women with severe anemia in labor: fetomaternal outcomes. Int $J$ Health Sci Res. 2022; 12(1):1-6. DOI: https://doi.org/10.52403/ ijhsr.20220101 